\title{
Patrimônio cultural e tombamento no Rio Grande do Sul: uma contribuição para os estudos urbanos
}

\author{
Cultural heritage and official historic landmarking in Rio Grande do Sul: \\ a contribution to urban studies
}

Daniel Luciano Gevehr, Gabriela Dilly

Faculdades Integradas de Taquara (FACCAT), Programa de Pós-graduação em Desenvolvimento Regional (PPGDR), Taquara, RS, Brasil

\section{Resumo}

0 artigo discute os processos de tombamento de 151 bens culturais pelo Instituto do Patrimônio Histórico e Artístico (IPHAE) do Estado do Rio Grande do Sul. Pretende-se analisar quais os mecanismos envolvidos na produção da memória, que busca, por meio dos bens tombados, criar lugares de memória, que, por sua vez, se apresentam diretamente associados ao planejamento dos diferentes espaços da cidade. Partimos do princípio de que a gestão do espaço é resultado de uma seleção e, nesse contexto, o patrimônio cultural presente nos espaços urbanos - também surge de escolhas. Discutem-se a dinâmica presente na eleição dos bens culturais e quais as suas áreas geográficas de maior concentração. Propõe-se, ainda, a interpretação desses espaços da cidade, enquanto lugares de memória, na medida em que, mediante suas denominações e organização próprias, revelam um complexo processo de manipulação da memória coletiva. 0 estudo pretende, ainda, discutir os desdobramentos desse processo que envolve a seleção desses lugares, para se pensar a cidade e seu patrimônio, com base no processo que envolve o planejamento.

Palavras-chave: Patrimônio cultural. Tombamento. Cidade.

\section{Abstract}

This article discusses the processes of declaring certain cultural properties into historic landmarks, naming 151 cultural properties by IPHAE - Historic and Artistic Heritage Institute of Rio Grande do Sul. The aim is to analyze which are the mechanisms involved in the production of memory, which seeks to form places of memory through historic landmarking declarations. These places seem to be directly associated with the planning and management of the different places around town. It is assumed that the management of such space is the result of a selection and in this context, the cultural heritage - present in the urban spaces - is also a result of such selections. It was discussed the dynamics present in the election of cultural properties and their main geographical areas of concentration. It is also proposed the interpretation of these spaces reveal a complex process of collective memory manipulation, due to their particular denominations and organization. Finally, this study intends to discuss the development of this process that involves these places, to think about the city and its patrimony from the process that involves planning.

Keywords: Cultural heritage. Official historic landmarking. City.

DLG é graduado e mestre em História, doutor em História, e-mail: danielgevehr@hotmail.com GD é graduada em história, mestranda em Desenvolvimento Regional, bolsista Capes, e-mail: gabidilly@hotmail.com 


\section{Introdução}

A pesquisa discute o processo que envolve a eleição do patrimônio cultural, segundo as políticas adotadas pelo Instituto do Patrimônio Histórico e Artístico do Estado (IPHAE), e busca pensar o território segundo o patrimônio cultural, que pode ser concebido como símbolo do passado da cidade e traduz, por meio de sua materialidade, discursos e formas de pensar o fenômeno urbano na contemporaneidade.

Discutimos o processo que envolve a criação de estratégias de planejamento voltadas ao patrimônio cultural do Rio Grande do Sul, mediante processos de tombamentos pelo IPHAE. Nosso propósito é analisar essas estratégias segundo a perspectiva do urbanismo (Choay, 2015), que busca compreender o fenômeno urbano também como uma produção cultural, que rompe com a concepção que considerou, até pouco tempo, essencialmente fatores de ordem econômica ou política.

Iniciamos discutindo a concepção de patrimônio cultural, que geralmente é considerado representativo da memória coletiva - uma vez que se parte do princípio, muitas vezes teórico - de que nele a comunidade se reconheça e se identifique com ele. Sabemos que essas questões são bastante complexas, tendo em vista que todo o patrimônio cultural oficializado, por processos de tombamento, é resultado de uma escolha. Sem dúvida, observamos que o patrimônio está diretamente ligado ao processo de planejamento dos espaços de uma cidade, na medida em que a cidade (Pesavento, 2002) é alvo de manipulações e (re)adequações.

Ao discutir as concepções de patrimônio - imbricadas nas questões do presentismo - Hartog (2014, p. 193) afirma que o patrimônio pode ser considerado uma forma de expressão do álter ego, ou seja, uma maneira de a sociedade expressar - material e imaterialmente - seus desejos, aspirações e necessidades. Isso nos leva a pensar o presente segundo as seleções patrimoniais que pretensamente manifestam o passado por meio de seu patrimônio, portanto passível de tombamento, que o elege e o consagra como parte de sua cultura.

No caso do Rio Grande do Sul, temos o IPHAE, responsável pelo planejamento dos bens considerados relevantes na história sul-rio-grandense, os quais, em geral, são tombados e protegidos por legislação específica, passam, dessa forma, a ser representativos de uma coletividade e marcam - dessa forma, os espaços da cidade (Sennett, 2003).

Constam na lista de tombamentos do IPHAE 151 bens culturais, distribuídos em diferentes municípios do estado. Em nosso estudo, que busca analisar o processo de seleção/planejamento dos tombamentos segundo a categoria de regionalização, pretendemos identificar as regiões do Rio Grande do Sul que possuem o maior número de itens tombados, bem como os espaços nos quais a memória passa a ser (i)materializada, se considerarmos o patrimônio material ou imaterial, por meio dos processos de tombamento, que buscam representar uma identidade sul-rio-grandense.

Buscamos, ainda, realizar um levantamento sobre os tipos de bens preservados e que memória estes sustentam - e fazem revelar nos espaços urbanos -, procurando relacioná-los a quais categorias pertencem, como religião, política, trabalho, cultura ou, ainda, ligados às personalidades da história do Rio Grande do Sul - que, nesse caso, possuem seus casarões perenizados pela instituição patrimonial. Um terceiro elemento de análise será o levantamento sobre os diferentes grupos étnicos com os quais esses bens patrimoniais estão associados e em que se materializa uma "memória da cidade".

Pretendemos ainda, estabelecer possíveis relações entre os bens tombados e as correntes historiográficas que deram sustentação a esses processos de tombamento - e, nesse caso, desempenharam papel fundamental como formadoras das matrizes historiográficas (Gutfreind, 1992; Elmir, 2011) no Rio Grande do Sul nas primeiras décadas do século XX. Buscamos compreender de que forma ocorrem a produção e a difusão dessa representação (Chartier, 2002) - materializada pelo tombamento nas cidades - e quais os discursos que se estabelecem por meio desses bens culturais, que procuram difundir certa representação do passado do Rio Grande do Sul.

Assume-se, portanto, uma postura crítica diante do tema, na medida em que pretendemos discutir a não neutralidade presente no processo de eleição/seleção desse patrimônio cultural, identificando-o como vetor de representações de poder (Bourdieu, 2001) diretamente articulado com os discursos da época na qual está inserido. Diante desses objetivos, é importante compreender quais as concepções aqui entendidas por patrimônio cultural e tombamento. Também se faz necessário traçar uma breve trajetória histórica do IPHAE - como instituição responsável pelo 
processo efetivo de tombamento no Rio Grande do Sul e promotora da preservação dos lugares de memória.

De acordo com a Constituição Federal de 1988, em seu artigo 216, considera-se patrimônio

[...] bens de natureza material e imaterial tomados individualmente ou em conjunto, portadores de referência à identidade, à ação, à memória dos diferentes grupos formadores da sociedade brasileira (Brasil, 1988).

Dessa forma, podemos pensar naquilo que Giovanaz (2007) afirma quando estabelece diversas correlações entre memória-identidade-patrimônio, em um tripé que desempenha um papel de suporte das representações humanas, de suas histórias e referenciais.

Podemos pensar ainda o patrimônio segundo a perspectiva apresentada por Pelegrini (2007), para quem a memória coletiva é um importante indicador para se definir o que deve ou não ser considerado patrimônio cultural. A autora afirma que estabelecer essa relação não é tão simples, uma vez que as memórias coletivas são atreladas a grupos e lugares, e as pessoas, na dinâmica de suas vidas, vão mudando, bem como os grupos aos quais pertencem, assim como as formas de compreender as materialidades à sua volta. Ressaltamos a necessidade de considerar as políticas que envolvem o planejamento (e seleção) dos bens culturais de uma comunidade e estão presentes no cotidiano da cidade - por meio de suas continuidades e descontinuidades (Sposito, 2014).

Por sua vez, Funari (2001) compreende que o patrimônio cultural é o que os antigos nos legaram por meio de uma cultura material e que serve de suporte das memórias e da identidade cultural de um grupo social. Segundo ele, deve-se considerar ainda o fato de que há uma relação de poder para estabelecer o que será o patrimônio cultural da nação e que este, na maioria das vezes, somente se identifica com as camadas sociais superiores. 0 autor continua sua argumentação dizendo que há agravantes para a questão, pois além de grande parte da população se sentir excluída em relação ao patrimônio cultural "nacional", que está identificado, na maioria das vezes, com as elites, acabou-se por desvalorizar as suas expressões culturais.

Com base nos estudos mais contemporâneos sobre patrimônio cultural (Castells \& Santos, 2014; Reis \& Figueiredo, 2015), percebemos que é compreendido como um conjunto muito complexo de concepções do que aquilo que referenda a própria Constituição Federal. Isso se explica na medida em que devemos considerar as relações que envolvem percepções de herança, tradição, representação da coletividade, identidade, etnia, referencial, materialidade, imaterialidade, memória, construção social, pertencimento, diversidade, poder e a própria concepção de nacionalidade em um país de dimensões continentais.

Diferentemente do caso nacional, em que, já em 1937, o patrimônio passa a ser um tema de interesse da esfera federal, no Rio Grande do Sul somente mais tarde é que surge um setor do governo específico para tratar das questões de patrimônio. Em 1964, foi criada a Diretoria do Patrimônio Histórico e Artístico do Estado do Rio Grande do Sul, responsável pela política de preservação dos bens patrimoniais e culturais do estado. Constituído atualmente como IPHAE, surgiu em 1979, sendo atualmente uma instituição vinculada à Secretaria de Cultura do Estado (Sedac) com várias funções, entre elas atender à demanda de tombamentos, elencando itens que comporão a lista de bens culturais representativos da memória e história do Rio Grande do Sul.

Atualmente, o IPHAE possui um corpo técnico composto de arquitetos, historiadores e geógrafos que precisam dar conta de uma diversidade cultural e peculiaridades muito distintas no cenário sul-rio-grandense. A equipe é responsável pelo planejamento e execução dos processos de tombamento do patrimônio cultural, distribuídos nas diferentes cidades do estado. A presença física desse patrimônio revela, ainda, os discursos presentes nessas cidades, que apresentam, por meio de seus bens tombados, uma visão sobre o urbano.

Precisamos esclarecer no que consiste o processo de tombamento, a que se refere sua inscrição no livro tombo. Em qualquer esfera, no uso de suas atribuições, o poder público pode utilizar o recurso do tombamento para garantir que um bem cultural seja preservado. Segundo o IPHAE, esse bem precisa ter valores arquitetônico e histórico agregados, no caso específico do patrimônio edificado. 0 tombamento é a forma mais utilizada por esferas governamentais mais amplas e comumente é encarado pela sociedade como a perda da propriedade (Borges, 2005).

0 tombamento é um ato público que dá origem a muita polêmica (Chuva, 2012), uma vez que esse ato implica permanências ou transformações que afetam diretamente o espaço urbano que o sustenta. Por sua 
vez, a sociedade discute até que ponto o governo possui a prerrogativa de interferir na relação entre o homem e sua propriedade, mas não percebe que o que está em pauta é maior que a propriedade privada, pois implica o bem comum, o interesse dos grupos sociais.

Partindo do raciocínio de que o bem tenha valor cultural para a comunidade, os titulares deste interesse são os indivíduos que compõem a coletividade, sendo este um interesse difuso (Borges, 2005, p. 3).

Há um número expressivo de bens tombados que pertencem ao poder público ou passam a pertencer após o tombamento com a aquisição dos locais. Ressalta-se que o tombamento de uma edificação gera um estudo de seu entorno a fim de estabelecer as restrições para que novas construções que venham ali se estabelecer não impeçam a visibilidade ao bem tombado, cuja paisagem deve poder ser usufruída por todos. Essa prerrogativa gera ainda mais debates, pois acaba por interferir em grandes áreas, às vezes localizadas em zonas de interesse imobiliário.

\section{Cidades, tombamentos e suas espacialidades}

Pretendemos relacionar os processos de tombamento com a geografia desses tombamentos - inscritos em diferentes cenários do estado -, identificando lugares que possuem maior número de bens tombados, e discutir acerca das hipóteses/motivações dessa distribuição espacial. Vale ressaltar que tal distribuição é resultado das escolhas feitas dentro dos setores responsáveis, que, em última instância, devem atender às demandas da sociedade civil e aos interesses dos diferentes grupos sociais envolvidos nesse processo. O planejamento e a execução desses processos são parte fundamental dessas escolhas.

Em um primeiro momento, valemo-nos de um mapa que estabelece a distribuição dos bens tombados no estado, agrupando-os pelas mesorregiões ${ }^{1}$. Esse mapa

\footnotetext{
${ }^{1}$ A Divisão Regional do Brasil em mesorregiões, partindo de determinações mais amplas em âmbito conjuntural, buscou identificar áreas individualizadas em cada uma das Unidades Federadas, tomadas como universo de análise, e definiu as mesorregiões com base nas seguintes dimensões: o processo social como determinante, o quadro natural como condicionante e a rede de comunicação e de lugares como elemento da articulação espacial (IBGE, 2010).
}

foi produzido pelo IPHAE e está disponível para consulta. A seguir, apresentamos a Figura $1 \mathrm{com}$ o mapa dos bens tombados no Rio Grande do Sul, agrupados por regiões.

Antes de tratar dos tombamentos e de sua organização espacial no Rio Grande do Sul, é importante considerar as diferentes definições de região - conceito essencial para a geografia e que, em nosso estudo, é fundamental para melhor compreendermos a dinâmica espacial dos bens tombados - pois regionalizar não é um conceito simples, podendo ser utilizado de diversas formas, com várias finalidades.

Müller (2000, p. 9) propõe o conceito de região como "[...] uma configuração escalar descentralizada da territorialidade global, que integra escalas de controle, de poder e de estratégias". De acordo com essa definição, percebemos que quem faz a regionalização são as redes e articulações de poder. A região não é dada, é uma construção social que envolve esferas de poder, de controle, além de questões políticas, econômicas, ambientais, sociais e culturais.

A culturalidade de um determinado espaço é, da mesma forma, uma construção. É forjada nas redes de influências dos grupos humanos, que buscam espaços de dominação, de poder, que dão origem aos territórios - ideia muito adequada ao presente estudo. Assim, "[...] o território seria uma área geográfica delimitada, na qual indivíduos e grupos produzem e influenciam e controlam uns aos outros" (Müller, 2000, p. 17). À definição desse conceito pode-se acrescentar que, além de controlar uns aos outros, controlam ainda o que está no espaço que ocupam, naquele território, o que inclui os bens culturais que devem ou não ser preservados, operando na manipulação das memórias e das narrativas sobre o passado, definindo o que será lembrado em um complexo exercício de poder.

De forma mais genérica, as mesorregiões levam em conta as ocupações históricas e econômicas do estado, implicando, para isso, o uso do critério cultural para estabelecer essa regionalização. Devemos observar aquilo que Toni \& Klarmann (2002, p. 4) afirmam quando esclarecem que o tipo de regionalização deve estar conectado com a finalidade de regionalizar, ou seja,

[...] quanto a opção pelo recorte teórico adotado (homogênea ou polarizada), que explicite claramente suas hipóteses sobre o espaço e - simultaneamente - tenha atributos de operacionalidade para instrumentalizar as políticas públicas de caráter regional. 


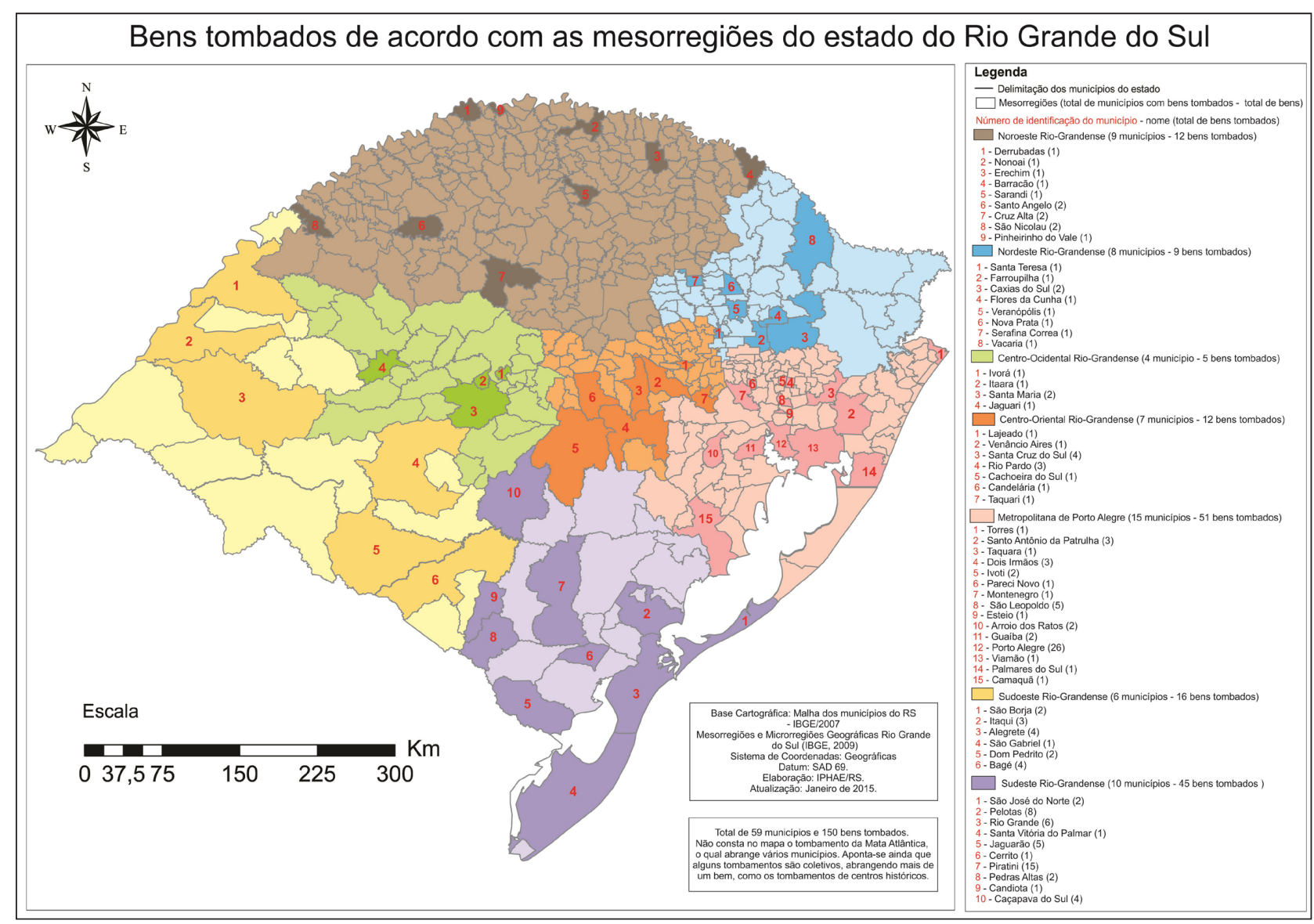

Figura 1 - Mapa dos bens tombados no Rio Grande do Sul, agrupados por regiões Fonte: IPHAE (2015).

No caso do Rio Grande do Sul, devemos considerar o fato de que

[...] a experiência administrativa estadual tem demonstrado que há inúmeros focos e tensões que propõem - de forma organizada ou meramente intuitiva - alterações sobre o "tabuleiro" regional que não questionam o padrão atual (Toni \& Klarmann, 2002, p. 16).

Ao considerarmos a discussão sobre as implicações do conceito de região e seus recortes, entendemos o patrimônio cultural sul-rio-grandense em uma perspectiva mais ampla - e não apenas geográfica -, buscando diversos elementos para analisar e compreender a dinâmica de produção e a seleção dos bens tombados pelo IPHAE. A localização geográfica dos bens traduz formas de pensar e ordenar o território.

Ao pensarmos essa questão, imputamos a discussão proposta por Guimarães (2013), para quem as práticas patrimoniais nos permitem compreender melhor parte dos discursos dos planejadores urbanos e dos projetos governamentais que norteiam as políticas voltadas ao tombamento e ao reconhecimento dos bens culturais.

Ainda que se perceba a complexidade, consideramos a distribuição espacial dos tombamentos, de acordo com o estabelecido pelo IPHAE, assim como as associações de ideias que a partir dela podemos estabelecer. De forma gráfica, percebemos a relação do número de tombamentos e suas respectivas regiões, conforme mostra a Figura 2, que apresenta os tombamentos no Rio Grande do Sul em proporcionalidade por mesorregião.

Fica evidente que temos duas regiões "privilegiadas", com uma quantidade expressiva de tombamentos. São os casos da região metropolitana de Porto Alegre e da região sudeste, que, na proporção de todo o estado, concentram conjuntamente, 96 dos 151 tombamentos. Nessas regiões, observa-se certa preocupação com o planejamento e a execução de políticas públicas 


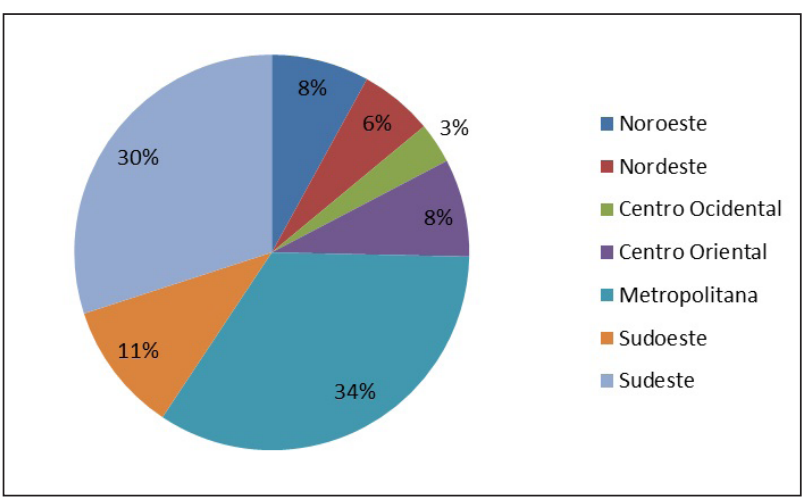

Figura 2 - Gráfico dos tombamentos no Rio Grande do Sul; proporcionalidade por mesorregĩ̃o

Fonte: Autores (2016).

voltadas ao patrimônio cultural, que produz novos significados sobre os espaços urbanos que sustentam essas materialidades.

Podemos estabelecer várias abordagens para tentar justificar essa expressiva concentração de bens tombados nas duas regiões mencionadas. É preciso destacar que são as duas regiões que concentram, respectivamente, a atual capital do estado - Porto Alegre - e uma das capitais farroupilhas - Piratini durante a Revolução Farroupilha (1835-1845). Dos 45 tombamentos da região sudeste, a maior parte se encontra em Piratini, que conta com 15 bens culturais registrados. Os dois municípios possuem um passado comum, com origens lusas, tendo sido povoados por açorianos ainda no século XVIII.

No caso da região sudeste do estado, constatamos que a memória preservada é essencialmente luso-brasileira, uma vez que remete diretamente ao passado da ocupação e colonização dessa região - onde atualmente ainda prevalece a atividade de pastoreio. Lá encontramos uma quantidade significativa de bens alusivos a nomes considerados "ilustres" da história sul-rio-grandense, bem como de pessoas das elites locais que possuem casas tombadas como referência arquitetônica.

Em Piratini é possível identificar tombamentos como a antiga casa, casa comercial e casa do comendador Fabião, a antiga moradia de Egydio Rosa, a casa de Gomes de Freitas, a casa de Vicente Lucas de Oliveira. Já em Pedras Altas, os tombamentos são do castelo e dos móveis de Pedras Altas, pertencentes à família de Joaquim Francisco de Assis Brasil, personagem considerado ilustre na memória local.
Pelotas - cuja geografia urbana procurou reproduzir a Paris do século XIX - é um dos municípios de maior expressão econômica na metade sul do estado e nele encontramos tombamentos como a antiga residência do Senador Augusto Assumpção e casa, castelo e palacete da família Simões Lopes. Próximo dali, em Caçapava do Sul, está protegida a casa de Antônio Augusto Borges de Medeiros, governador do estado de 1898 a 1928 - conhecido como a Era Borges.

Todos os antigos proprietários desses bens foram membros da elite gaúcha em diferentes épocas e destacaram-se como militares, intelectuais e burgueses, exercendo importantes papéis como lideranças. Essa percepção nos leva a acreditar que persistem resquícios fortes de influências historicistas, entendidas como conservadoras - visto que o Rio Grande do Sul foi um dos estados no qual o ideal positivista se fez mais expressivo no início do século XX e essa forte influência se verificou na produção historiográfica até pelo menos a década de 1970 (Soares, 1998) - nos processos de tombamento do Rio Grande do Sul, uma vez que parte desses processos procura exaltar vultos da história sulina. Dos 22 bens culturais tombados referentes a vultos históricos em todo o estado, 12 ficam na região sudeste do Rio Grande do Sul, revelando uma leitura tradicional da história que se associa à permanência de uma estrutura campesina, na qual as antigas famílias - que deram origem ao povoamento da região - ainda são, em parte, proprietárias das fazendas.

Acreditamos que a seleção dos itens preservados apresenta resquícios da concepção historiográfica tradicional historicista e/ou positivista que preservou interesses das elites regionais que produziram discursos que legitimaram narrativas sobre o passado sul-rio-grandense, cuja produção historiográfica foi marcada pelos grandes feitos dos vultos históricos, que exaltavam a imagem dos militares nas Revoluções Farroupilha (1835-1845) e Federalista (1893-1895), além de reafirmar seu caráter como formadores das fronteiras do Brasil meridional.

No processo de manipulação e operação da memória, atentamos ao fato de que o positivismo e o historicismo são

[...] frutos de uma mesma necessidade de época, representada pelo paradoxo de encaminhar uma modernização política que viabilizasse aquele desenvolvimento industrial que atenderia às exigências da burguesia triunfante e ao mesmo 
tempo conservar alguns privilégios sociais da nobreza (Barros, 2012, p. 86-87).

Trata-se de uma visão romântica e glorificadora do passado que dá origem a narrativas locais, com sérios problemas teóricos, mas amplamente difundidas nos municípios - gerando memórias manipuladas e criando mitos.

Já a região metropolitana possui outra configuração espacial no que diz respeito às suas políticas de enquadramento e preservação da memória. Por ser uma região do estado densamente povoada e constituída por diferentes grupos étnicos, o quadro que se apresenta é mais diversificado.

Nessa região, temos diversos tombamentos que podem ser compreendidos como indicativos do caráter precocemente urbano. Referem-se a lugares públicos, destacando-se usinas termoelétricas, hidrelétricas e o gasômetro, assim como construções que abrigaram seminários, escolas e bibliotecas, imóveis pertencentes à viação férrea, provedorias, arquivos públicos, bancos, hospitais, hotéis, praças, teatros, cinema, associações comerciais e a conhecida ilha do antigo presídio. Nessa região, há uma política forte de preservação que aponta para a valorização da história da industrialização, dos transportes, dos caminhos e do abastecimento energético, além de um aparato cultural bastante amplo e diversificado que procura tornar rememorável a intensa vida social.

Como exemplo, encontramos o tombamento da Ilha do Presídio em Porto Alegre, ocorrido em 2014, para preservar as memórias atreladas às expressões sociais mais sombrias, uma vez que no século XIX o local foi usado como casa de pólvora, para mais tarde virar presídio de segurança máxima, passando a operar até como centro de repressão do Departamento de Ordem Política e Social (DOPS) - palco de torturas e prisões políticas de 1965 a 1973 (IPHAE, 2016).

Esse tipo de tombamento não é comum, por se tratar de uma lembrança que geralmente se prefere esquecer ou pelo menos não dar maior visibilidade social. Pollak $(1989$, p. 8) se refere a essa questão como sendo "a fronteira entre o dizível e o indizível, o confessável e o inconfessável”. Esse tombamento executado pelo IPHAE em 2014 pode ainda ser interpretado na perspectiva proposta por Pollack (1989, p. 8), para quem “[...] uma memória coletiva subterrânea da sociedade civil dominada ou de grupos específicos, de uma memória coletiva organizada que resume a imagem que uma sociedade majoritária ou o Estado desejam passar e impor".
O reconhecimento formal e institucional de um lugar de memória (Nora, 1993) como esse é significativo, atestando a real função do tombamento, que é representar uma memória coletiva (Halbwachs, 2003). 0 processo de tombar lugares - que marcam materialmente os espaços - advém da necessidade de criar referenciais da memória, preocupando-se com a perpetuação de parte das memórias da cidade.

Compreendemos que os lugares de memória

[...] nascem e vivem do sentimento que não há memória espontânea, que é preciso criar arquivos, que é preciso manter aniversários, organizar celebrações, pronunciar elogios fúnebres, notariar atas, porque essas operações não são naturais (Nora, 1993, p. 13).

Nessa categoria se inserem os tombamentos, que podem ser compreendidos como "vigilantes da história", suportes da memória, na medida em que partimos da ideia de que "[...] a memória pendura-se em lugares, como a história em acontecimentos" (Nora, 1993, p. 25).

Já a ideia de memória coletiva segue a teoria proposta por Halbwachs (2003), para quem a memória coletiva se apoia na memória individual, que, por sua vez, ancora-se nas lembranças e nas imagens do passado, geradas nas materialidades das nossas cidades, como praças, prédios e ruas. Atentamos, ainda, ao fato de que

[...] se, entre as casas, as ruas e os grupos de seus habitantes houvesse apenas uma relação muito acidental e de curta duração, os homens poderiam destruir suas casas, seu bairro, sua cidade, segundo um plano diferente (Halbwachs, 2003, p. 163).

Sem dúvida, essa é uma importante dimensão para se pensar a produção do espaço urbano.

Nesse contexto,

[...] quando um grupo humano vive por muito tempo em um local adaptado a seus hábitos, não apenas a seus movimentos, mas também seus pensamentos se regulam pela sucessão de imagens materiais que os objetos exteriores representam [...] (Halbwachs, 2003, p. 163)

o tombamento de determinados bens culturais pode revelar essas formas de pensar e sentir a materialidade presente nesses espaços sociais, que se tornam visíveis à comunidade que os compartilha cotidianamente. 
Um exemplo dessa complexa relação pode ser observado no caso da região metropolitana, onde encontramos grande preocupação com a produção e difusão da representação das etnias lusa - como é o caso da capital e seus arredores - e alemã, como é o caso da maioria dos municípios do Vale dos Sinos.

\section{Geografia das cidades, tombamentos e sua etnicidade}

De acordo com Abreu (2014), após um longo período no qual se valorizava apenas aquilo que era "novo na cidade", o cotidiano urbano brasileiro percebeu a necessidade de elaborar projetos que definiram a valorização e a preservação dos vestígios do passado.

Assim como as demais regiões geográficas do Brasil, o Rio Grande do Sul é constituído por um conjunto multicultural que inicia sua configuração demográfica com a presença de indígenas, espanhóis, portugueses e africanos. No século XIX, inserido no contexto de disputas territoriais e de defesa das fronteiras, o Rio Grande do Sul passa a receber imigrantes europeus que acabam desempenhando um importante papel de formadores de fronteira, em defesa dos interesses imperiais no Brasil meridional. Nesse momento, iniciou-se o processo de colonização com imigrantes alemães, italianos, russos, poloneses, judeus, japoneses e outras minorias étnicas que ocuparam diferentes regiões do estado.

Dos grupos étnicos que chegaram ao Rio Grande do Sul nessa fase da imigração e colonização, foram os alemães e italianos aqueles que vieram em maior número. Em razão disso, observaremos uma intensa relação entre os processos de tombamento de bens culturais associados a esses grupos étnicos, uma vez que são nessas áreas - de imigrações alemã e italiana - que encontraremos um expressivo número de municípios que preservam a memória imigrante.

Partimos da ideia de que etnia ou etnicidade (Poutignat \& Streitff-Fenart, 1998) são conceitos fundamentais, por meio dos quais podemos compreender a relação existente entre os processos de tombamentos e a preservação de memórias e sentimentos associados à identidade étnica de determinados grupos. Com isso, partimos da definição proposta por Seyferth (2011, p. 47), para quem "[...] a delimitação teórica agrega a identidade (e seus aspectos subjetivos) e a noção de fronteira (social) que delimita o pertencimento a um grupo ou comunidade", gerando, assim, a ideia de etnicidade.
A constituição da identidade dessas comunidades não está ligada somente à sua origem étnica, mas também a outras práticas sociais, costumes, hábitos familiares e ao próprio fazer das tradições (Thompson, 2013), que, por sua vez, são preservadas, atualizadas e (re)passadas (Candau, 2012) de geração em geração, com diferentes elementos, e, assim, constituem o processo de construção das suas memórias e de suas identidades. Nesse caso, o tombamento exerce um papel primordial, na medida em que permite dar visibilidade a essas práticas culturais - inscritas nos espaços urbanos e também rurais da contemporaneidade -, ao mesmo tempo que assegura a sua perpetuação através do tempo. Nesse complexo exercício de rememoração do passado, ocorre, ainda, um processo de atualização da memória (Catroga, 2011), na qual a herança deixada pelos antepassados é ressignificada pelas atuais gerações, que, por meio do processo de tombamento, conferem significado especial ao bem cultural, na mesma medida em que oficializa e assegura a preservação do bem tombado pelo poder público, que reconhece o bem não mais apenas na esfera local, mas o torna de interesse regional, uma vez que quem o torna oficial é o IPHAE.

Ao partirmos dessas concepções teóricas, analisamos em que medida os bens tombados materializam - ou não - essa composição étnica e em que medida temos elementos mensuráveis para realizar tal discussão, uma vez que, segundo Seyferth (2011), é praticamente impossível mensurar o que, de fato, é étnico ou pode representar elementos de um grupo étnico específico.

Na Figura 3, aproximamos essa discussão, selecionando os bens culturais tombados segundo a categoria da etnicidade. Tomamos como referência o lugar - nesse caso mais específico, o município em questão - em que se localiza o bem tombado. Percebemos claramente a presença expressiva de bens culturais que remetem diretamente à cultura de origens lusa, alemã e italiana.

Os demais grupos étnicos aparecem em menor proporcionalidade, reafirmando a ideia de que o processo de patrimonialização - e consequente tombamento por parte do IPHAE - obedece a uma lógica complexa, inscrita no campo das relações de poder, e que dá visibilidade a determinadas narrativas sobre $o$ passado - que encontram respaldo em algumas matrizes historiográficas (Gutfreind, 1992) do Rio Grande do Sul que reforçam a história das presenças lusa, alemã e italiana, como elementos formadores da identidade 


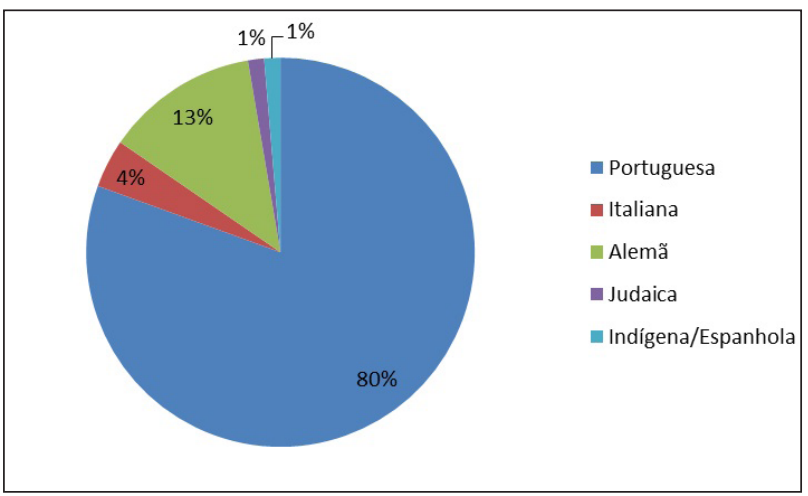

Figura 3 - Gráfico dos tombamentos conforme a etnia Fonte: Autores (2016).

sul-rio-grandense. De forma esquemática, a Figura 3 mostra os tombamentos conforme sua etnia.

Torna-se evidente a predominância do registro e da proteção de bens culturais relacionados à presença lusa no Rio Grande do Sul, considerada por alguns representantes da historiografia sul-rio-grandense "formadores de sua argamassa étnica" (Wiederspahn, 1979, p. 131), ou seja, a representação da identidade étnica por excelência. Observamos que essa mesma opinião aparece de forma recorrente entre outros autores que compõem, dessa forma, o mosaico de representações historiográficas até o final da década de 1980 acerca da presença lusa no sul do Brasil. Como exemplo dessa corrente historiográfica, podemos citar autores como Barbosa (1985), César (1998) e Laytano (1948).

Em nosso estudo, devemos considerar que o Estado brasileiro teve uma relação ambígua com os imigrantes, que deveriam se estabelecer e atender às demandas governamentais de vínculo com a terra, defesa das fronteiras, produção econômica e "branqueamento" da população. Esses elementos teriam por finalidade melhorar as qualidades morais e físicas do brasileiro, em um processo identificado por Seyferth (2002) como eugenia racial.

Como no caso da historiografia produzida sobre os lusos no Rio Grande do Sul, encontramos obras de referência - que, assim como no caso dos lusos, foi produzida também até meados da década de 1980 - sobre os processos de imigrações alemã e italiana. Em grande medida, contribuíram para difundir essas ideias autores como Amstad (1924), Canstatt (1967), Davatz (1941), Oberacker (1954), Porto (1934), Schröder (2003) e Moog (2005) - no caso da imigração alemã - e Adami (1970), De Boni \& Costa (1984), Dacanal (1980), Manfroi (1975),
Merlotti (1979) e Santos (1980) no caso na imigração italiana no Rio Grande do Sul.

Citamos alguns estudiosos da imigração que influenciaram as visões que se construíram e se difundiram nas áreas de imigração, nas quais se manifestou, de forma bastante evidente, um discurso que apontava para o enaltecimento desse pertencimento étnico.

Valorizar o patrimônio do imigrante europeu - nesse caso mais específico dos alemães e italianos - significa dar visibilidade ao que deveria submeter-se aos preceitos nacionais, ao que não deveria "destoar" do conceito pensado sobre a nação, "[...] colonos extremamente distanciados do ideal brasileiro de nação e dos quais se exigia a assimilação" (Seyferth, 2002, p. 127). Cabe lembrar que ao mesmo tempo que as autoridades julgavam ser necessária a entrada dos imigrantes, havia certo medo desses grupos, tanto que eles possuíam diversas liberdades cerceadas, principalmente no que se refere à liberdade de credo, de expressão e ao controle dos núcleos - quistos - de imigrantes, especialmente durante o Estado Novo (1937-1945), período em que alemães e italianos eram vistos como potenciais ameaças aos valores nacionais do governo Vargas.

Durante o período de nacionalização, estabelece-se no país um discurso que se pretende hegemônico em relação a ideia de nacionalidade, que deverá ser lusa, católica e de língua portuguesa. Nesse período, não surpreende que a predominância dos tombamentos também o seja. Também parece adequado ao poder público não criar pontos de referência indígena, africana ou espanhola - etnias encontradas no processo de formação dos municípios do Rio Grande do Sul -, mas, em linhas gerais, restaram poucas materialidades de sua presença, podendo destacar como exceção a esse processo o complexo das Missões Jesuíticas, já considerado patrimônio histórico da humanidade pela Unesco, não necessitando de novo registro no livro tombo do IPHAE.

A Unesco faz escola para outros órgãos de patrimônio, [...] pois cerca de mais de $50 \%$ dos bens reconhecidos pela Unesco como patrimônio mundial da humanidade encontram-se no continente europeu e $60 \%$ do total de bens listados situam-se na Europa e na América do Norte" (Pelegrini, 2007, p. 96)

indicando que o que acontece no Rio Grande do Sul é reflexo, em grande parte, da visão eurocêntrica afirmada e reproduzida cotidianamente, em muitas das escolas e meios de comunicação. 
Atentamos ao fato de não ser necessário existirem vestígios materiais para ocorrer tombamentos, uma vez que a imaterialidade também é contemplada no conceito contemporâneo de patrimônio cultural, sendo eles apenas catalogados em um índice de referências culturais. Festejos, tradições, culinária, danças e cantos também são expressões culturais que podem - e devem - ser registradas mediante reconhecimento e proteção oficiais, justamente pelo fato de serem acessíveis e fazerem parte das manifestações culturais de diferentes grupos sociais.

De acordo com Pelegrini (2008, p. 152),

[...] as políticas públicas de preservação adotadas nas últimas décadas do século XX pautaramse na ampliação do conceito de patrimônio, atualmente compreendido como os bens de caráter natural, imaterial e material (móvel ou imóvel).

É preciso reconhecer a preocupação com o tombamento do patrimônio natural pelo IPHAE, que registrou o Parque Florestal Estadual Espigão Alto, de Barracão, Parque Florestal Estadual do Turvo, em Derrubadas, Parque Florestal Estadual de Nonoai, em Nonoai, Parque Florestal de Rondinha, em Sarandi, e a Mata Atlântica e seus ecossistemas associados em vários municípios do estado.

Ao observar esses tombamentos se percebe a receptividade do IPHAE quanto à ampliação do conceito de patrimônio anteriormente referida, mas falta ainda encontrar mecanismos efetivos para proteger as tradições não tangíveis dos diferentes grupos étnicos - e de forma especial das diferentes etnias indígenas e africanas que ocuparam o espaço sul-rio-grandense. Estes se mostraram desfavorecidos pelo não reconhecimento de seu patrimônio cultural. Decorre disso a necessidade de dar a devida importância ao patrimônio imaterial, que

[...] representa um grande passo no sentido de reconhecer que a diversidade cultural é inerente ao povo brasileiro, e que toda essa heterogeneidade constitui, essencialmente, a base onde se produz e se reproduz o patrimônio cultural" (Aguinaga, 2006, p. 8).

Ampliando a discussão, tomamos as ideias de Chagas (2002), que procura estabelecer, de acordo com os debates sobre patrimonialização, a relação entre memória e poder, alertando para "qual o discurso" proferido nas entrelinhas e que, por sua vez, é
[...] composto de som e silêncio, de cheio e vazio, de presença e ausência, de lembrança e esquecimento, implica a operação não apenas com o enunciado da fala e suas lacunas, mas também a compreensão daquilo que faz falar, de quem fala e do lugar de onde fala" (Chagas, 2002, p. 43).

\section{Produção dos espaços da cidade e tombamentos}

Outro elemento em nossa investigação refere-se à análise do contexto histórico e dos tipos de tombamentos encontrados no Rio Grande do Sul, buscando distinguir as categorias empregadas nesse processo de tombamento. Definimos os diferentes tipos de bens culturais tombados conforme as seguintes categorias: museus, residências, espaços de trabalho, espaços de sociabilidade, centros históricos, palácios/palacetes, espaços de mobilidade, parques, igrejas, hospitais, espaços militares, escolas, entre outros - que nos permitem compreender melhor as escolhas realizadas pelo IPHAE no processo de tombamento dos bens culturais. A seguir, a Figura 4 mostra os tombamentos por categoria.

Ao observarmos a Figura 4, percebemos a significativa presença de residências, palácios e casarões, bem como espaços de trabalho e lugares associados às atividades religiosas. Aventamos a possibilidade de que o discurso mais recorrente é aquele que aponta para o tombamento arquitetônico que privilegia, pelo menos em parte, o patrimônio material das elites que

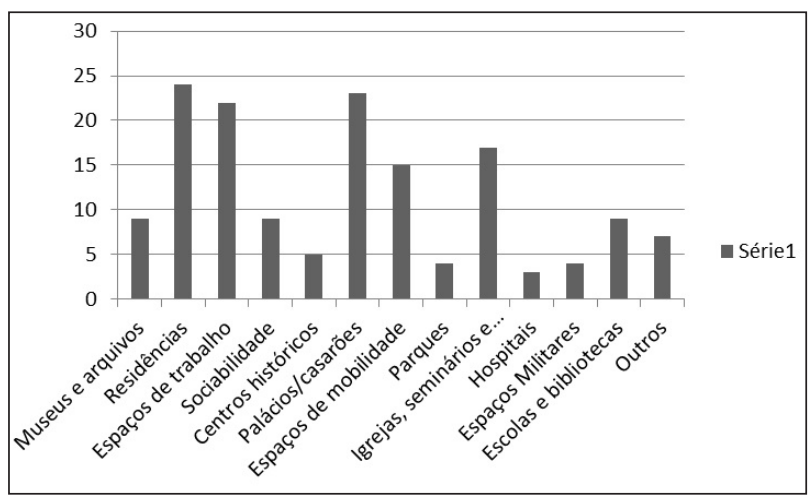

Figura 4 - Tombamentos por categoria Fonte: Autores (2016). 
tiveram condições de erguer casas com arquitetura singular, representativa de uma época.

A questão da representação - e suas relações com o campo de poder - também se insere nesse universo, uma vez que "[...] as representações não são discursos neutros: produzem estratégias e práticas tendentes a impor uma autoridade, uma deferência e mesmo a legitimar escolhas" (Carvalho, 2005, p. 149). Perceber em um bem tombado a representação de sua identidade não é algo fácil de ser percebido, uma vez que ocorre, muitas vezes, segundo imposições dos grandes projetos nacionais que buscam, não raras vezes, imprimir uma memória única e homogênea.

Em parte, os tombamentos dos bens culturais no Rio Grande do Sul constituem um discurso de "empoderamento" das elites tradicionais gaúchas, ligadas à antiga aristocracia lusa e, depois, à burguesia - de forte caráter étnico, em especial de alemães e italianos - que se constituiu no processo de industrialização do estado. Esse aspecto nos faz refletir sobre a necessidade de reverter essa situação, e a resposta parece indicar a necessidade de um sistemático trabalho de educação patrimonial (Magalhães, 2009, p. 67). Busca-se, com isso, fazer que a sociedade perceba que possui seu próprio patrimônio cultural, presente nos bairros, nas cidades e nas tradições, que são agentes do fazer histórico.

Para Giovanaz (2007, p. 239), o propósito das políticas de preservação está no fato de que

[...] veja o passado como um direito do cidadão é resgatar aquelas ações e até mesmo as utopias não realizadas, fazendo-as emergir ao lado da memória do poder e em contestação ao seu triunfalismo.

É preciso fazer uma importante ressalva em nossa análise, compreendendo que o panorama atual sobre tombamentos no estado é resultado de um entendimento sobre patrimônio cultural ainda bastante tradicional. Ao observarmos a Figura 5, podemos verificar os períodos em que foram executados os tombamentos, considerando sua inscrição no livro tombo do IPHAE.

$\mathrm{Na}$ cronologia dos registros, percebemos que a maior parte dos tombamentos se concentra na década de 1980, período de saída da ditadura militar e de intenso processo de crescimento industrial e urbanização. Essa dinâmica de transformação exerceu papel fundamental nas políticas patrimoniais do Rio Grande do Sul, produzindo sensíveis mudanças no processo de manipulações das identidades do gaúcho

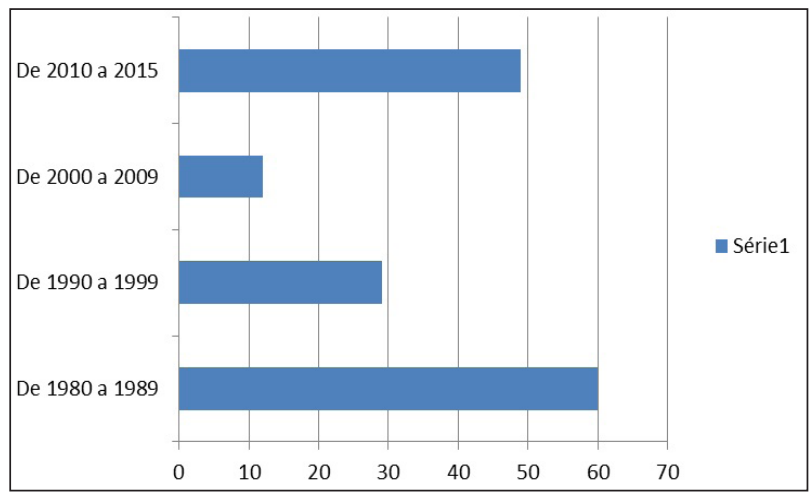

Figura 5 - Tombamentos por período

Fonte: Autores (2016).

- grandes grupos sociais deslocaram-se para áreas urbanas com demandas de emprego nas indústrias e diferentes setores do terciário.

Em diferentes municípios do estado, o rápido crescimento dos bairros e o aumento do comércio, do trânsito de pessoas e de mercadorias produziu, progressivamente, um novo contexto, cada vez mais articulado com a globalização. Nele, observa-se que as comunidades procuraram "segurar o tempo" (Giovanaz, 2007, p. 239) que lhes escorria por entre as mãos, sentindo-se "ameaçados" quanto à perda de sua configuração cultural, o que era inevitável. 0 tombamento surge, assim, como uma forma de "travar a aceleração" e garantir alguma permanência ante as mudanças.

A década de 1980 caracteriza-se pelo grande debate sobre patrimônio cultural, ainda entendido como exclusivamente material e pouco crítico, mas que teve grande importância, levando muitas comunidades - como é o caso do Rio Grande do Sul - a realizar um levantamento acerca de seus lugares de memória (Nora, 1993). Ao observarmos a Figura 5, percebemos que, em termos de proporcionalidade, a década atual acompanha uma retomada nas ações de tombamento no estado.

0 desafio - para pensar a cidade segundo sua relação com o patrimônio - é encontrar mecanismos efetivos de valorização do patrimônio imaterial, tão suscetível ao esquecimento, mas de relevância identitária, e que, dessa forma, contribuem para

[...] estabelecer um conceito de memória e de história que transcendem os tradicionais conceitos de patrimônio e, principalmente, que incluam em seus discursos as experiências dos 
grupos sociais marginalizados pela antiquada concepção [...] (Giovanaz, 2007, p. 240).

Outras memórias também se fazem presentes nos espaços da cidade - que se percebem pelo patrimônio e pelos tombamentos. Nesses espaços físicos da cidade aparecem, inevitavelmente, as memórias da elite, mas também as memórias dos trabalhadores como no caso dos tombamentos de edificações que rememoram os lugares do trabalho e das diferentes atividades profissionais, ou até mesmo o mundo do trabalho rural ou urbano. Dessa forma, a cidade revela, por meio de seu patrimônio, parte de suas escolhas e seleções.

\section{Considerações finais}

Nosso estudo problematizou a relação existente entre o patrimônio cultural e seu processo de preservação, por meio do tombamento, segundo a perspectiva dos estudos sobre o fenômeno da produção do espaço urbano. Em suas diferentes concepções, o urbanismo (Choay, 2015) permitiu compreender melhor os mecanismos presentes na elaboração de estratégias voltadas à gestão dos bens culturais de uma cidade.

Quando analisamos as ações de tombamento realizadas pelo IPHAE, lembramos que os tombamentos são atos políticos que fazem parte de um jogo de poder que reflete parte dos interesses da sociedade - ou de parte dela - e, assim como ela, se estabelece, sendo a cultura utilizada para manter os discursos de poder.

Não questionamos nem estabelecemos juízos de valor sobre o funcionamento do IPHAE no que se refere às ações específicas de seus profissionais, cujo trabalho tem demonstrado, progressivamente, o reconhecimento dos debates mais atuais em relação ao patrimônio. Procuramos evidenciar a importância do estabelecimento de políticas públicas de preservação do patrimônio que potencializem ações de planejamento e de gestão das cidades. A execução dessas ações permite pensar em inúmeras possibilidades de desenvolvimento social, econômico e cultural, inscritas, por sua vez, no campo dos estudos urbanos contemporâneos - em especial, em suas escalas local e regional.

Reconhecemos que existe uma longa caminhada em direção à inclusão social do patrimônio cultural, na qual diferentes grupos sociais ainda não têm o devido reconhecimento de seus espaços sociais de memória, bem como de sua identidade. Daí decorre o fato de que o patrimônio cultural não tem valor intrínseco, mas sim assume o valor que os grupos sociais lhe atribuem. A ação seletiva da memória é tanto individual quanto coletiva, mas o que não deveria ocorrer é que as opções por preservar ou não incidam, na maioria das vezes, sobre um mesmo grupo social - as elites locais ou regionais -, quando alguns são lembrados e outros, esquecidos.

0 que jamais deve cair no esquecimento é que o patrimônio cultural é um direito de todos, visto que faz parte do referencial de vida das pessoas que circulam pela cidade, dá noção de pertencimento e autoestima - dá sentido ao espaço vivido. A dimensão pública do tombamento garante a preservação do invólucro, mas não gera o conteúdo, dado que este é gerado por ações cotidianas das comunidades, é dinâmico e nos constitui enquanto cidadãos.

A presença - ou ausência - de políticas voltadas à preservação do patrimônio cultural nos permite pensar sobre a dinâmica que envolve a produção dos espaços urbanos no Rio Grande do Sul e em que medida o patrimônio cultural tem sido contemplado nas discussões sobre planejamento e gestão das cidades.

\section{Referências}

Abreu, M. (2014). Sobre a memória das cidades. In A. F. A. Carlos, M. L. Souza \& M. E. B. Sposito (Eds.), A produção do espaço urbano: agentes e processos, escalas e desafios (p. 147-166). São Paulo: Contexto.

Adami, J. S. (1970). História de Caxias do Sul: 1864-1970 (2. ed.). Caxias do Sul: São Miguel.

Aguinaga, K. F. S. (2006). A proteção do patrimônio cultural imaterial e os conhecimentos tradicionais. In Anais do XV Congresso Nacional do CONPEDI/UEA. Manaus: CONPEDI. Recuperado em 17 de dezembro de 2015, de http://www. publicadireito.com.br/conpedi/manaus/arquivos/anais/ manaus/estado_dir_povos_karyn_s_aguinaga.pdf

Amstad, T. (1924). A imigração alemã no Rio Grande do Sul. Porto Alegre: Hugo Metzler.

Barbosa, F. D. (1985). História do RS (3. ed.). Porto Alegre: Escola Superior de Teologia São Lourenço de Brindes/ Martins Livreiro.

Barros, J. D. A. (2012). Historicismo: notas sobre um paradigma. Antíteses, 5(9), 391-419. Recuperado em 17 de 
abril de 2016, de http://www.uel.br/revistas/uel/index. php/antiteses/article/view/8154/11412

Borges, M. A. (2005). 0 tombamento como instrumentos jurídicos para a proteção do patrimônio cultural. Revista Jurídica., 7(73), 1-4. Recuperado em 17 de abril de 2016, de http://www.presidencia.gov.br/ccivil_03/revista/ Rev_73/artigos/MarcoAntonio_rev73.htm

Bourdieu, P. (2001). O poder simbólico (4. ed.). Rio de Janeiro: Bertrand Brasil.

Brasil. (1988, 5 de outubro). Constituição da República Federativa do Brasil de 1988. Brasília: Diário Oficial da União. Recuperado em 17 de janeiro de 2016, de http:// www.planalto.gov.br/ccivil_03/constituicao/constituicao.htm

Candau, J. (2012). Memória e identidade. São Paulo: Contexto. Canstatt, O.(1967). Repertório crítico da literatura teutobrasileira. Rio de Janeiro: INL.

Carvalho, F. A. L. C. (2005). 0 conceito de representações coletivas segundo Roger Chartier. Revista Diálogos, 9(1), 143-165.

Castells, A. N. G., \& Santos, J. L. C. (Eds.). (2014). Patrimônio cultural e seus campos. Florianópolis: UFSC.

Catroga, F. (2011). Os passos do homem como restolho do tempo: memória e fim do fim da história (2. ed.). Coimbra: Almedina.

César, G. (1998). Primeiros cronistas do RS: 1605-1801 (3. ed.). Porto Alegre: UFRGS.

Chagas, M. (2002). Memória e poder: dois movimentos. Cadernos de Sociomuseologia, 19(19), 43-81. Recuperado em 17 de abril de 2016, de http://revistas.ulusofona.pt/ index.php/cadernosociomuseologia/article/view/367/276

Chartier, R. (2002). À beira da falésia: a história entre certezas e inquietude. Porto Alegre: UFRGS.

Choay, F. (2015). O urbanismo: utopias e realidades uma antologia (7. ed.). São Paulo: Perspectiva.

Chuva, M. (2012). Preservação do patrimônio cultural no Brasil: uma perspectiva histórica, ética e política. In M. Chuva, \& G. R. Nogueira (Eds.), Patrimônio Cultural: políticas e perspectivas de preservação no Brasil (p. 67-78). Rio de Janeiro: Mauad/Faperj.

Dacanal, J. H. (1980). Imigração e colonização. Porto Alegre: Mercado Aberto.
Davatz, T. (1941). Memórias de um colono no Brasil. São Paulo: Livraria Martins.

De Boni, L. A., \& Costa, R. (1984). Os italianos no RS (3. ed.). Caxias do Sul: EDUCS/EST.

Elmir, C. P. (2011). A produção historiográfica no RS nos últimos 50 anos (1961-2010). In Anais do XXVI Simpósio Nacional de História (p. 1-15). São Paulo: ANPUH.

Funari, P. P A. (2001). Os desafios da destruição e conservação do Patrimônio Cultural no Brasil. Trabalhos de Antropologia e Etnologia, 41(1-2), 23-32.

Giovanaz, M. (2007). Pedras e emoções: os percursos do patrimônio. Em Questão, 13(2), 235-242.

Guimarães, R. S. (2013). Urban interventions, memories and conflicts: black heritage and the revitalization of Rio de Janeiro's Port Zone. Vibrant, Virtual Brazilian Anthropology, 10(1), 208-227. http://dx.doi.org/10.1590/ S1809-43412013000100011.

Gutfreind, I. (1992). A historiografia rio-grandense. Porto Alegre: UFRGS.

Halbwachs, M. (2003). A memória coletiva (5. ed.). Campinas: Editora da UNICAMP.

Hartog, F. (2014). Regimes de historicidade: presentismo e experiências do tempo. Belo Horizonte: Autêntica.

Instituto Brasileiro de Geografia e Estatística - IBGE. (2010). Censo Demográfico 2010. Rio de Janeiro: IBGE. Recuperado em 17 de abril de 2016, de http://www.ibge.gov.br/home/ geociencias/geografia/default_div_int.shtm?c=1

Instituto do Patrimônio Histórico e Artístico do Estado IPHAE. (2015). Municípios com bens tombados pelo IPHAE. Porto Alegre: IPHAE. Recuperado em 20 de março de 2016, de http://www.iphae.rs.gov.br/Main.php?do=DownloadD etalhesAc\&item $=46802$

Instituto do Patrimônio Histórico e Artístico do Estado - IPHAE. (2016). Bem tombado. Porto Alegre: IPHAE. Recuperado em 17 de abril de 2016, de http://www. iphae.rs.gov.br/Main.php?do=BensTombadosDetalhesA c\&item $=56800$

Laytano, D. (1948). Açorianos e Alemães no Desenvolvimento da Colonização e Agricultura do RS. Porto Alegre: Globo.

Magalhães, L. H. (2009). Educação patrimonial: uma análise conceitual. In L. H. Magalhães, E. R. Zanon, \& P. M. C. Branco (Eds.),. A construção de políticas patrimoniais: 
ações preservacionistas de Londrina, Região Norte do Paraná e Sul do país (p. 65-67). Londrina: EdUniFil.

Manfroi, O. (1975). A colonização italiana no RS: implicações econômicas, políticas e culturais. Porto Alegre: Grafosul/IEL.

Merlotti, V. B. (1979). O mito do padre entre descendentes de imigrantes italianos. Porto Alegre: Grafosul.

Moog, V. (2005). Um rio imita o Reno. Porto Alegre: IEL.

Müller, G. (2000). A descentralização na globalização. Revista Redes, 5(2), 9-25.

Nora, P. (1993). Entre memória e história: a problemática dos lugares. Projeto História, 10, 7-28.

Oberacker, C. H. (1954). Die Sozialgeschischtliche Beteutung der Deutschen Einwanderung. Staden-Jahrbuch. São Paulo: Instituto Hans Staden.

Pelegrini, S. C. A. (2007). O patrimônio cultural e a materialização das memórias individuais e coletivas. Revista Patrimônio e Memória, 3(1), 87-100. Recuperado em 17 de abril de 2016, de http://pem.assis.unesp.br/ index.php/pem/article/viewFile/33/459

Pelegrini, S. C. A. (2008). A gestão do patrimônio imaterial brasileiro na contemporaneidade. História, 27(2), 145-173.

Pesavento, S. (2002). O imaginário da cidade: visões literárias do urbano: Paris, Rio de Janeiro, Porto Alegre (2. ed.). Porto Alegre: UFRGS.

Pollak, M. (1989). Memória, esquecimento, silêncio. Estudos Históricos, 2, 3-15.

Porto, A. (1934). O trabalho alemão no Rio Grande do Sul. Porto Alegre: Est. Graf. S. Terezinha.

Poutignat, P., \& Streitff-Fenart, J.(1998). Teorias da Etnicidade seguido de Grupos Étnicos e suas Fronteiras de Frederik Barth. São Paulo: Editora da UNESP.

Reis, A. S., \& Figueiredo, B. G. (Ed.). (2015). Patrimônio imaterial em perspectiva. Belo Horizonte: Fino Traço.
Santos, J. V. T. (1980). Cantineiros e colonos: a indústria do vinho no RS. In E. C. Barros (Ed.), RS: imigração \& colonização (p. 135-155). Porto Alegre: Mercado Aberto.

Schröder, F. (2003). A imigração alemã para o sul do Brasil (2. ed.). Porto Alegre: PUCRS/UNISINOS.

Sennett, R. (2003). Carne e pedra: o corpo e a cidade na civilização ocidental (3. ed.). Rio de Janeiro: Record.

Seyferth, G. (2002). Colonização, imigração e a questão racial no Brasil. Revista da USP, 53(53), 117-149. http:// dx.doi.org/10.11606/issn.2316-9036.v0i53p117-149.

Seyferth, G. (2011). A dimensão cultural da imigração. Revista Brasileira de Ciências Sociais, 26(77), 47-62. http:// dx.doi.org/10.1590/S0102-69092011000300007.

Soares, M. P. (1998). O positivismo no Brasil: 200 anos de Augusto Comte. Porto Alegre: AGE/UFRGS.

Sposito, M. E. B. (2014). A produção do espaço urbano: escalas, diferenças e desigualdades socioespaciais. In A. F. A. Carlos, M. L. Souza, \& M. E. B. Sposito (Eds.), A produção do espaço urbano: agentes e processos, escalas e desafios (p. 123-145). São Paulo: Contexto.

Thompson, E. P. (2013). Costumes em comum: estudos sobre cultura popular e tradicional. São Paulo: Cia. Das Letras.

Toni, J., \& Klarmann, H. (2002). Regionalização e planejamento, reflexões metodológicas e gerenciais sobre a experiência gaúcha. Revistas Eletrônicas FEE, 23, 1-19. Recuperado em 17 de abril de 2016, de http://cdn.fee.tche.br/eeg/1/ mesa_3_toni_klarmann.pdf

Wiederspahn, H. O. (1979). A Colonização Açoriana no RS. Porto Alegre: Escola Superior de Teologia São Lourenço de Brindes/Instituto Cultural Português.

Recebido: Maio 02, 2016

Aprovado: Jun. 27, 2016 